Check for updates

Cite this: Chem. Sci., 2019, 10, 2805

๑ All publication charges for this article have been paid for by the Royal Society of Chemistry

Received 2nd November 2018 Accepted 12th January 2019

DOI: $10.1039 / \mathrm{c} 8 \mathrm{sc} 04891 \mathrm{f}$

rsc.li/chemical-science

\section{In situ visualization of ozone in the brains of mice with depression phenotypes by using a new near-infrared fluorescence probe $\uparrow$}

\author{
Ping Li, \$ Jijuan Wang, \$ Xin Wang, Qi Ding, Xiaoyi Bai, Yandi Zhang, Di Su, Wei Zhang, \\ Wen Zhang and Bo Tang (D) *
}

Ozone $\left(\mathrm{O}_{3}\right)$, one of the reactive oxygen species (ROS), is deeply involved in diseases including depression. However, the lack of appropriate in situ detection methods suitable for the complex biological context of brain impedes uncovering the exact relationship between depression and changes in the $\mathrm{O}_{3}$ level. Therefore, we developed a near-infrared (NIR) fluorescent probe (ACy7) for the direct visualization of $\mathrm{O}_{3}$ in mice brains. The specific cycloaddition reaction between $\mathrm{O}_{3}$ and the terminal double bond of the butenyl group extends the conjugation of the "pre-" heptamethine cyanine system, which emits NIR fluorescence of heptamethine cyanine. This makes the ACy7 specific, highly sensitive and able to deeply penetrate tissue. Using ACy7, we found that under glutamate stimulation, the $\mathrm{O}_{3}$ content in PC12 cells was significantly higher than that in control cells. By imaging analysis on the brains of mice, we revealed for the first time that the levels of $\mathrm{O}_{3}$ in mice with depression phenotypes were markedly higher than that in control mice. Intriguingly, experimental results unravelled that excess $\mathrm{O}_{3}$ promoted high expression of the pro-inflammatory cytokine interleukin-8 (IL-8), which ultimately induced depression phenotypes. Our work demonstrates the pivotal role of elevated $\mathrm{O}_{3}$ in depression and provides a fresh entry point for exploring oxidative stress contributing to depression.

\section{Introduction}

Depression is a mental illness affecting people throughout the world, causing high mortality and disability rates. ${ }^{1}$ However, the aetiology of depression is still unclear. In recent years, the immunoinflammatory hypothesis of depression has received increasing attention. This hypothesis suggests that inflammatory mediators such as cytokines play an important role in the development of depression and that the immunoinflammatory reaction may be an essential cause of the poor efficacy of conventional antidepressant treatments., ${ }^{2,3}$

As one of the reactive oxygen species (ROS), ozone $\left(\mathrm{O}_{3}\right)$ has attracted widespread attention due to its key role in mental disorders, ${ }^{4-7}$ such as depression. Unfortunately, there are two different perspectives on the relationship between $\mathrm{O}_{3}$ and depression. Some researchers have shown that exogenous $\mathrm{O}_{3}$ stimulation induces depressive behaviors. ${ }^{8-11}$ Others have

College of Chemistry, Chemical Engineering and Materials Science, Key Laboratory of Molecular and Nano Probes, Ministry of Education, Collaborative Innovation Center of Functionalized Probes for Chemical Imaging in Universities of Shandong, Institutes of Biomedical Sciences, Shandong Normal University, Jinan 250014, People's Republic of China. E-mail: tangb@sdnu.edu.cn

$\dagger$ Electronic supplementary information (ESI) available: Synthetic procedures, cells/mice culture, and additional figures. See DOI: 10.1039/c8sc04891f

\$ These authors contributed equally to this work. shown that ozonation in conjunction with autologous blood transfusion could be used as a new, fast acting antidepressant treatment. ${ }^{12} \mathrm{O}_{3}$ is endogenously produced in the inflammation and antibacterial response of the immune system, ${ }^{\mathbf{1 3}, \mathbf{1 4}}$ which causes the production of cytokines, including the proinflammatory cytokine interleukin-8 (IL-8), amplifying the inflammatory cascade. ${ }^{15}$ So, we speculate that during depression, the level of endogenous $\mathrm{O}_{3}$ in the brain is increased, resulting in the overexpression of $\mathrm{IL}-8$, which is the ultimate cause of depression. To confirm our hypothesis and clarify the role of $\mathrm{O}_{3}$ in depression, the development of appropriate in vivo detection methods to in situ visually monitor changes in $\mathrm{O}_{3}$ in brains of mice with depression phenotypes is of special note.

Fluorescent probes are characterized by high sensitivity, relatively simple preparation, and good biocompatibility, and therefore they have been used to observe target molecules in living organisms. ${ }^{\mathbf{1 6 - 2 0}}$ In particular, optical imaging associated with the near-infrared (NIR) fluorescent probe has the advantages of being suitable for deep tissue penetration and low autofluorescence background, making this technique more applicable for in vivo detection. ${ }^{21}$ In recent years, fluorescent probes for monitoring $\mathrm{O}_{3}$ have been developed, but these probes are mostly used for detecting $\mathrm{O}_{3}$ at the environmental or the cellular level. ${ }^{22-26}$ Due to the complex biological environment in the brain and the blood-brain barrier, probes for measuring $\mathrm{O}_{3}$ in living brains have not been reported. 
Thus, we designed and synthesized an "off-on" NIR smallmolecule fluorescent probe (ACy7) for high sensitivity fluorescence imaging of $\mathrm{O}_{3}$ in the brains of mice with depression phenotypes. Our probe uses a Cy7-like molecule as the precursor of the fluorophore and 3-butenyl as the recognition group. ${ }^{26} \mathrm{O}_{3}$ can undergo a specific cycloaddition reaction with the terminal olefin of the 3-butenyl moiety to convert ACy7 to the quinone derivative QCy7, extending the degree of conjugation. This reaction triggers emitting bright, NIR fluorescence of heptamethine cyanine (Scheme 1), allowing the specific and highly sensitive detection of $\mathrm{O}_{3}$. We first explored the applicability of ACy7 in macrophages and PC12 cells. Then, we applied ACy7 to the in situ fluorescence imaging of $\mathrm{O}_{3}$ in the brains of mice with depression phenotypes. In addition, we investigated the molecular mechanisms of depression associated with $\mathrm{O}_{3}$ regulation of IL-8 involvement.

\section{Results and discussion}

\section{In vitro optical properties of $\mathrm{ACy} 7$ to $\mathrm{O}_{3}$}

ACy7 was synthesized by a two-step reaction (Scheme S1, ESI $\dagger$ ), purified by thin-layer chromatography and column chromatography, and then characterized by ${ }^{1} \mathrm{H}$ NMR, ${ }^{13} \mathrm{C}$ NMR and MS. To understand the effect of $\mathrm{O}_{3}$ on the photophysical properties of ACy7, we first measured the absorption spectra of the probe in the absence and presence of $\mathrm{O}_{3}$. As shown in Fig. S1a (ESI $\dagger$ ), the absorption maximum of the probe was at approximately $420 \mathrm{~nm}$ in the absence of $\mathrm{O}_{3}$. When $\mathrm{O}_{3}$ was added to the system, the probe exhibited a new absorption band at approximately $570 \mathrm{~nm}$, and the intensity of the absorption at $570 \mathrm{~nm}$ enhanced with increasing $\mathrm{O}_{3}$ concentration. Subsequently, we studied the fluorescence properties of QCy7. Fig. S1b (ESI†) shows that the maximum excitation and emission peaks of QCy7 are at $570 \mathrm{~nm}$ and $690 \mathrm{~nm}$, respectively, with a large Stokes shift. We examined the fluorescence response of $\mathrm{ACy} 7$ to $\mathrm{O}_{3}$ and optimized the reaction conditions (Fig. S2-S5, ESI†). We measured the fluorescence emission intensities of $\mathrm{ACy} 7$ before and after the addition of $\mathrm{O}_{3}$ (Fig. 1A). The figure shows that when the reaction solution did not contain $\mathrm{O}_{3}$, the fluorescence emission of the probe at $690 \mathrm{~nm}$ was negligible. When $\mathrm{O}_{3}$ solution is added to the mixture, the fluorescence emission intensity of the probe at $690 \mathrm{~nm}$ is significantly enhanced, increasing by more than 80fold. This indicates that the probe has a high signal to noise ratio. This result is consistent with the design of our probe, tuning fluorescence from "off" to "on" by extending the conjugation of the "pre-" heptamethine cyanine system. As depicted

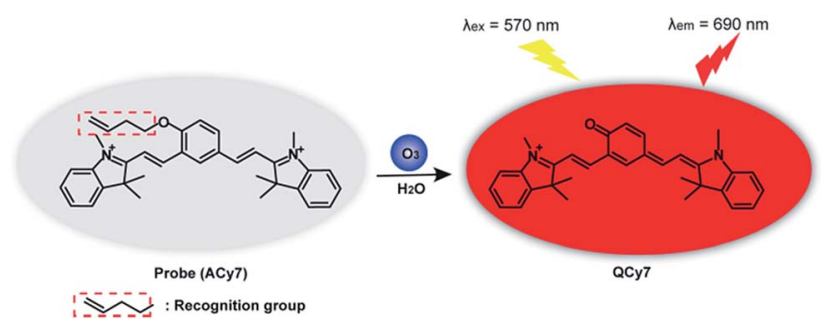

Scheme 1 "Off-on" type NIR fluorescent probe ACy7 reaction with $\mathrm{O}_{3}$.
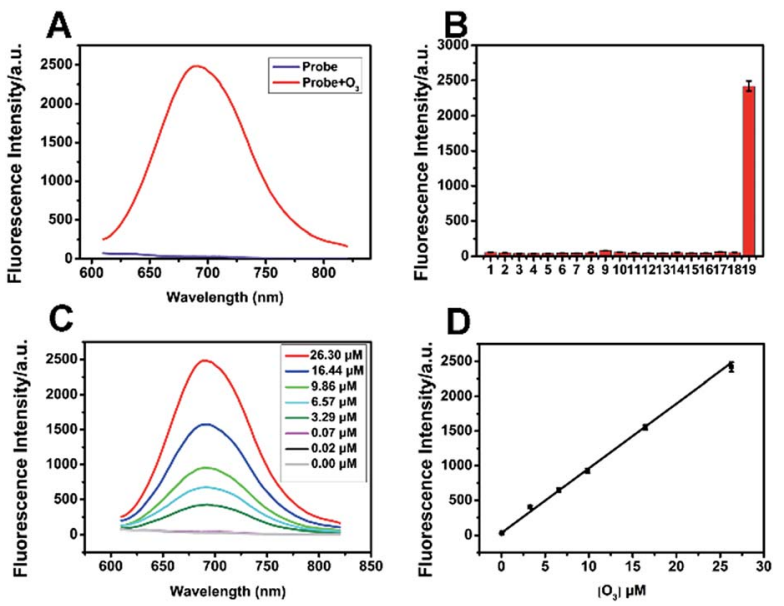

Fig. 1 Fluorescence spectral properties of ACy7. (A) Fluorescence emission spectrum of $10 \mu \mathrm{M}$ ACy7 before and after reaction with $\mathrm{O}_{3}$ $(26.30 \mu \mathrm{M})$. (B) Fluorescence responses of $10 \mu \mathrm{M}$ ACy7 to some biological interfering substances. (C) Fluorescence response of $10 \mu \mathrm{M}$ ACy7 after the addition of serial concentrations of $\mathrm{O}_{3}$. (D) $\mathrm{A}$ linear relationship between the fluorescence emission intensity of the ACy7 solution and the $\mathrm{O}_{3}$ concentration $\left(\lambda_{\mathrm{ex}} / \lambda_{\mathrm{em}}=570 / 690 \mathrm{~nm}\right)$. Error bars are $\pm \mathrm{SD}(n=3)$. (Interfering substances: (1) blank, (2) $\mathrm{H}_{2} \mathrm{O}_{2}(0.1 \mathrm{mM})$, (3) $\mathrm{O}_{2} \cdot-(125 \mu \mathrm{M}),(4){ }^{1} \mathrm{O}_{2}(50 \mu \mathrm{M}),(5) \cdot \mathrm{OH}(50 \mu \mathrm{M}),(6) t-\mathrm{BuOOH}(30 \mu \mathrm{M})$, (7) $\mathrm{NaClO}(50 \mu \mathrm{M}),(8) \mathrm{NO}(50 \mu \mathrm{M}),(9) \mathrm{ONOO}^{-}(6 \mu \mathrm{M}),(10) \mathrm{GSH}(5 \mathrm{mM})$, (11) vitamin $C(0.3 \mathrm{mM}),(12) \mathrm{Na}^{+}(0.5 \mathrm{mM}),(13) \mathrm{K}^{+}(0.5 \mathrm{mM}),(14) \mathrm{Zn}^{2+}$ (0.5 mM), (15) $\mathrm{Ca}^{2+}(0.5 \mathrm{mM}),(16) \mathrm{Na}_{2} \mathrm{~S}_{2} \mathrm{O}_{3}(0.5 \mathrm{mM}),(17) \mathrm{Fe}^{3+}(0.5 \mathrm{mM})$, (18) citric acid $(50 \mu \mathrm{M})$, and (19) $\mathrm{O}_{3}(26.30 \mu \mathrm{M})$.)

in Scheme S2 $\left(\mathrm{ESI}_{\dagger}^{\dagger}\right)$, through a $(3+2)$ cycloaddition reaction, the terminal olefin of probe 1 reacts with $\mathrm{O}_{3}$ to form molecular ozonide 2, which further generates aldehyde $3, \mathrm{HCHO}$ and $\mathrm{H}_{2} \mathrm{O}_{2}$ in the aqueous solution. Then, aldehyde 3 undergoes $\beta$-elimination to produce $\mathrm{CH}_{2}=\mathrm{CHCHO}$ and compound 4 . Phenate compound 4 undergoes electron rearrangement to form a fluorescent quinone derivative QCy7. ${ }^{27}$ This specific reaction mechanism can endow the probe with outstanding selective and sensitive response to $\mathrm{O}_{3}$.

Under the optimal conditions, we added various concentrations of $\mathrm{O}_{3}$ to the ACy7 reaction solution. As expected, the fluorescence emission intensity of QCy7 at $690 \mathrm{~nm}$ gradually increased with increasing $\mathrm{O}_{3}$ concentration. The $\mathrm{O}_{3}$ concentration and fluorescence emission intensity $(\Delta F)$ showed good linearity in the range of $0.02-26.30 \mu \mathrm{M}$ (Fig. 1C and D). The linear correlation equation was $\Delta F=93.23\left[\mathrm{O}_{3}\right](\mu \mathrm{M})+29.50\left(R^{2}\right.$ $=0.9964)$. The limit of detection $(3 S / k$, in which $S$ is the standard deviation of the blank measurements, $n=11$, and $k$ was the slope of the linear equation) was $10 \mathrm{nM}$. To further confirm that the turn-on fluorescence is based on the probe reacting with ozone, we carried out RP-HPLC analysis combined with MS to detect the conversion of ACy7 before and after reaction with an equimolar amount of ozone (Fig. S6, ESI $\dagger$ ). The results of HPLC-MS verify that $33 \%$ of ACy7 transformed to QCy7 with an equimolar amount of ozone, causing a notable increase in fluorescence. These findings demonstrate that the probe can measure low concentration of $\mathrm{O}_{3}$ with high sensitivity.

To evaluate the specificity of the reaction, we examined some interfering substances that are common in the biological 
environment, such as ROS, reactive nitrogen species (RNS), bioantioxidants and metal ions, under the same conditions (Fig. 1B). When these interfering substances were added, the fluorescence intensity of the probe was extremely low. The addition of $\mathrm{O}_{3}$ brought about obvious fluorescence enhancement, indicating that the probe has good specificity and can specifically detect $\mathrm{O}_{3}$. In addition, we examined the reaction kinetics and photostability of ACy7 to $\mathrm{O}_{3}$. As shown in Fig. S7 (ESI $\dagger$ ), when $\mathrm{O}_{3}$ was added, the emission intensity of the ACy7 solution reached a plateau at approximately $40 \mathrm{~min}$, and the intensity remained basically unchanged over the next $25 \mathrm{~min}$. The fluorescence emission intensity of ACy7 basically did not change with time. Therefore, ACy7 can quickly react with $\mathrm{O}_{3}$ and has good photostability. These results indicate that the probe (ACy7) has desirable properties, including emission located in the NIR region, high sensitivity and high specificity. Therefore, ACy7 is expected to be suitable for in situ detection and bioimaging of $\mathrm{O}_{3}$ in biological samples.

\section{Endogenous $\mathrm{O}_{3}$ imaging in live cells with ACy7}

The above studies on the optical properties of ACy7 in vitro proved that ACy7 was well suited for the detection of $\mathrm{O}_{3}$ under simulated physiological conditions. To test the feasibility of the probe ACy7 as an imaging reagent, its potential toxicity to cells was evaluated using a standard MTT [3-(4,5-dimethylthiazol-2yl)-2,5-diphenyl-tetrazolium bromide] assay (Fig. S8, ESI $\dagger$ ). ${ }^{28}$ The results showed that $\mathrm{ACy} 7 \mathrm{had}$ an $\mathrm{IC}_{50}$ value of $0.322 \mathrm{mM}$, meaning low cytotoxicity.

Then, the applicability of ACy7 for the imaging of RAW 264.7 macrophages was investigated. We firstly tried to visualize exogenous $\mathrm{O}_{3}$ within living macrophages. Macrophages were incubated directly in $5 \mu \mathrm{M}$ of $\mathrm{O}_{3}$ solution, and then fluorescence brightness was examined (Fig. 2B). The images showed that the fluorescence intensity within these cells was 1.5 -fold stronger than that of the control (Fig. 2A). This result indicates that the probe ACy7 can be used for imaging of exogenous $\mathrm{O}_{3}$ at the cellular level. To investigate whether the probe ACy7 is capable of monitoring endogenous $\mathrm{O}_{3}$ in cells, phorbol 12-myristate 13acetate (PMA) was used to stimulate macrophages for producing $\mathrm{O}_{3}$ (Fig. 2C). ${ }^{29}$ As expected, intracellular fluorescence intensity was 1.9-fold higher than that of the control. To verify that the enhancement of fluorescence intensity was caused by an increase in $\mathrm{O}_{3}$, we added ethyl 4-vinylbenzoate to eliminate intracellular $\mathrm{O}_{3}$ (Fig. 2D). ${ }^{15}$ We observed that the fluorescence intensity of these cells was significantly reduced (by 1.9-fold) compared to that of the PMA-stimulated group. This experiment further proves that the endogenous $\mathrm{O}_{3}$ produced in the cells undergoes a cleavage reaction with ACy7 to release QCy7 to emit light instead of reacting with other ROS. The above results demonstrate that our probe has sufficient membrane permeability and can be used for imaging changes in intracellular $\mathrm{O}_{3}$.

To investigate the feasibility of ACy7 in nerve cell applications, we visualized the changes in endogenous $\mathrm{O}_{3}$ levels inside PC12 cells. Considering that glutamate can cause nerve cells to undergo oxidative stress with concomitant ROS production, ${ }^{30}$ high concentration glutamate was added to the cells (Fig. 3C). We found that the fluorescence signal within these cells significantly increased (8.6-fold) compared with that of the control. This result indicates that excess of $\mathrm{O}_{3}$ is produced in glutamate-stimulated cells, and ACy7 can be used to image endogenous $\mathrm{O}_{3}$ in PC12 cells. To further demonstrate that the change in the fluorescence intensity was caused by $\mathrm{O}_{3}$, we preincubated the cells with ethyl 4-vinylbenzoate (Fig. 3B and D), and found that the fluorescence intensity of these cells was greatly lower than that of the control. The imaging of PC12 cells showed that ACy7 can effectively distinguish between control cells and cells under oxidative stress. Overall, the results of the cell imaging experiments demonstrate that ACy7 has the advantages of membrane permeability and biocompatibility.

\section{Fluorescence imaging of $\mathrm{O}_{3}$ in the brains of mice with depression phenotypes}

Since the emission of the probe is in the NIR region, it causes only slight light damage to biological samples. In particular, it could penetrate deeper tissue with weak background fluorescence interference. These merits make ACy7 well suited for in vivo imaging experiments. Therefore, we explored in vivo fluorescence imaging of $\mathrm{O}_{3}$ with the probe. First, we established a chronic unpredictable mild stress (CUMS) mouse model (Fig. S9-S11, ESI $\dagger$ ). ${ }^{31}$ After successful modelling, both control mice and mice with depression-like behaviors were injected intraperitoneally with $0.15 \mathrm{mg} \mathrm{kg}{ }^{-1}$ of ACy7. Subsequently, in
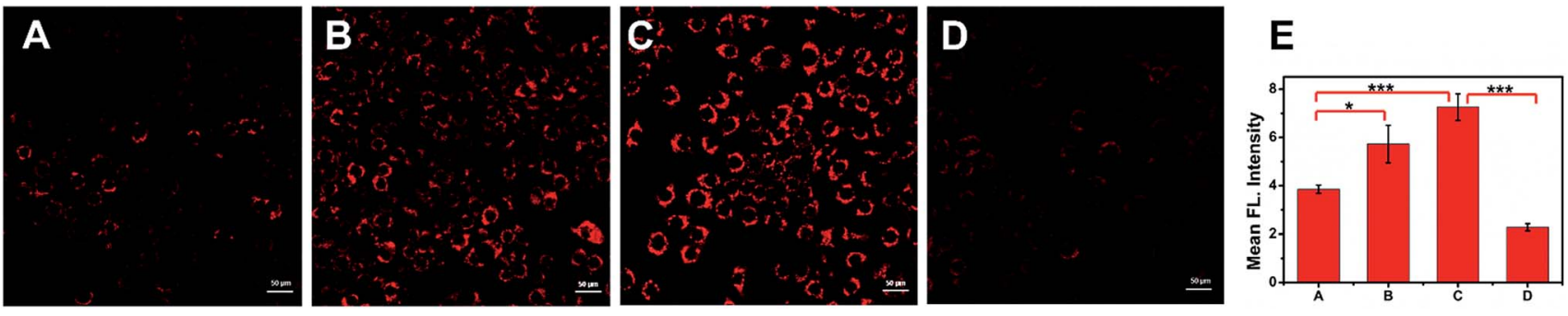

Fig. 2 Laser confocal imaging of $\mathrm{O}_{3}$ in RAW 264.7 macrophages. (A) Cells incubated with $10 \mu \mathrm{MACy} 7$ for 15 min at $37^{\circ} \mathrm{C}$. (B) ACy7-loaded cells incubated with $5 \mu \mathrm{M} \mathrm{O}_{3}$ for $10 \mathrm{~min}$. (C) Cells incubated with PMA (100 ng mL ${ }^{-1}$ ) for 20 min and then incubated with $10 \mu M$ ACy7 at $37{ }^{\circ} \mathrm{C}$ for $15 \mathrm{~min}$. (D) Cells incubated with PMA (100 ng mL $\left.{ }^{-1}\right)$ for $20 \mathrm{~min}$, and then with $0.05 \mathrm{mM}$ ethyl 4-vinylbenzoate for $30 \mathrm{~min}$, and then with $10 \mu \mathrm{M}$ ACy7 for $15 \mathrm{~min}$. (E) The data output of the graphs in (A)-(D). All cells were washed 3 times with $0.01 \mathrm{M}$ PBS prior to imaging. Emissions from $640 \mathrm{~nm}$ to $740 \mathrm{~nm}$ were collected using a $561 \mathrm{~nm}$ laser. The values are the mean $\pm \mathrm{s} . \mathrm{d}$. for $n=3, * p<0.05$, and *** $p<0.001$. 

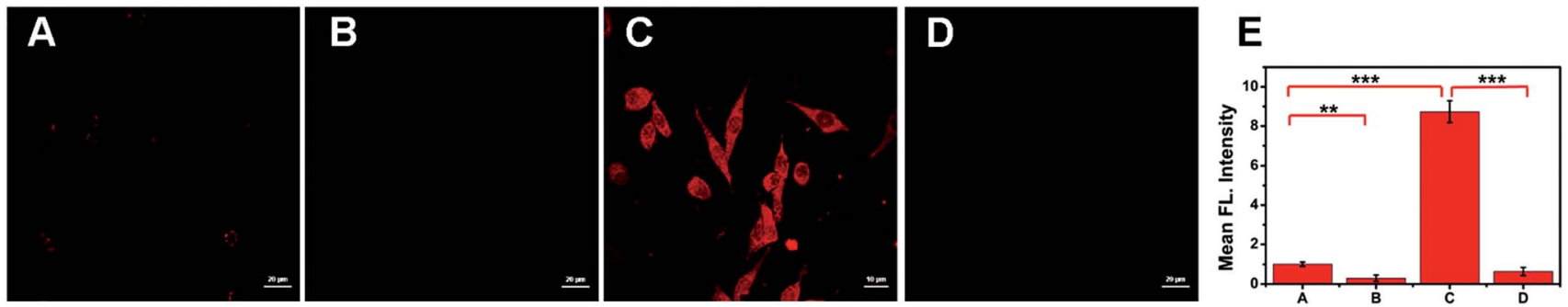

Fig. 3 Laser confocal imaging of $\mathrm{O}_{3}$ in $\mathrm{PC} 12$ cells. (A) Cells incubated with $10 \mu \mathrm{M} \mathrm{ACy} 7$ for 15 min at $37^{\circ} \mathrm{C}$. (B) Cells incubated with $0.05 \mathrm{mM}$ ethyl 4-vinylbenzoate and then treated according to (A). (C) Cells incubated with $10 \mathrm{mM}$ glutamate for $17 \mathrm{~h}$ and then incubated with ACy7 for $15 \mathrm{~min}$ at $37^{\circ} \mathrm{C}$. (D) Cells incubated with $10 \mathrm{mM}$ glutamate for $17 \mathrm{~h}$, and then with $0.05 \mathrm{mM}$ ethyl 4 -vinylbenzoate for $30 \mathrm{~min}$ and then with $\mathrm{ACy} 7$ for $15 \mathrm{~min}$. (E) The data output of the graphs in (A)-(D). All cells were washed 3 times with $0.01 \mathrm{M}$ PBS prior to imaging. Emissions from $640 \mathrm{~nm}$ to $740 \mathrm{~nm}$ were collected using a $561 \mathrm{~nm}$ laser. The values are the mean \pm s.d. for $n=3, * * p<0.01$, and $* * * p<0.001$.

situ fluorescence imaging of the brain of each mouse was performed using an IVIS Lumina III (Fig. 4). The results showed that the brain of mice with depression-like behaviors exhibited brighter fluorescence, about 1.8-times higher than that of control mice. This indicates that the $\mathrm{O}_{3}$ contents in the brains of mice with depression-like behaviors are higher than the levels in control mice. Overall, based on the superior in vivo fluorescence imaging performance of the probe $\mathrm{ACy} 7$, we revealed the elevation of $\mathrm{O}_{3}$ in the brains of mice with depression phenotypes for the first time.

\section{Study of the signalling pathway of $\mathrm{O}_{3}$-induced depression phenotypes in mice}

We have demonstrated that the level of $\mathrm{O}_{3}$ in the brain of mice is positively correlated with depression phenotypes. We wondered why the flux of $\mathrm{O}_{3}$ is associated with depression-like behaviors. Studies have shown that $\mathrm{O}_{3}$ as one of the important ROS is deeply involved in inflammation. ${ }^{32-34}$ In the meantime, there is a close relationship between inflammation and depression. ${ }^{35,36}$ So, we speculated that IL-8 served as a bridge between $\mathrm{O}_{3}$ and depression. To verify this assumption, we analysed IL-8 in the brains of mice with depression-like behaviors. First, we used lipopolysaccharide (LPS) to establish a mouse model of acute inflammation-induced depression (Fig. S12-S14, ESI†), ${ }^{37}$ and
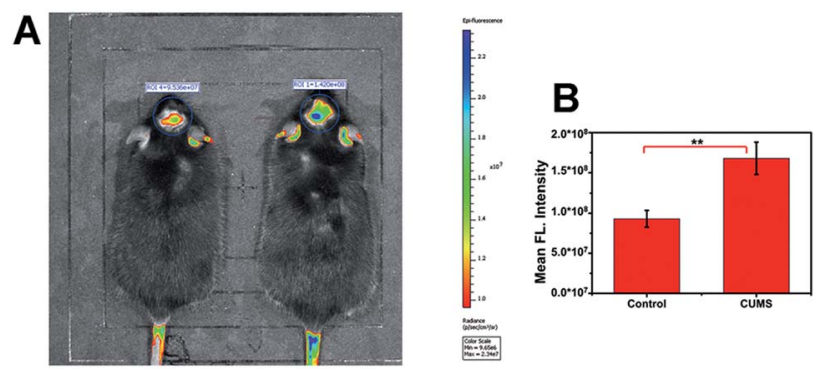

Fig. 4 Visual imaging of $\mathrm{O}_{3}$ in the brains of mice. (A) Fluorescence imaging (pseudocolor) of $A C y 7$ in control mice (left) and mice with depression-like behaviors (right). (B) The output of the fluorescence intensity in image (A). The excitation wavelength filter is $570 \mathrm{~nm}$, and the emission wavelength filter is $690 \mathrm{~nm}$. The values are the mean \pm s.d. for $n=3$, and $* * p<0.01$. divided the mice into a control group, an LPS group and an LPS + Lim group. We next injected $0.15 \mathrm{mg} \mathrm{kg}^{-1}$ of ACy7 into the mice by intraperitoneal injection and performed in situ fluorescence imaging of the mouse brains using an IVIS Lumina III (Fig. 5A and B). The images showed higher fluorescence intensity in the brain tissue of the mice with depression-like behaviors, 1.9-fold greater than that of the control group. Similar results were also obtained by utilizing sulfo-ACy7 (Fig. S15, ESI $\dagger$ ). This means the obvious increase in $\mathrm{O}_{3}$ in depression caused by inflammation.

Next, to investigate how IL-8 levels changed in the brains of mice, we measured the IL- 8 content in the brain of each mouse by enzyme linked immunosorbent assay (ELISA) (Fig. 5C). The results showed that the IL-8 contents in mice with depressionlike behaviors were 1.7-fold greater than those in the control group, indicating that the increase in IL-8 in the brains of mice with depression-like behaviors is caused by inflammation. To prove that the changes in the IL- 8 contents in the brains of mice are ascribed to $\mathrm{O}_{3}$, we used limonene (Lim, a natural $\mathrm{O}_{3}$ scavenger) to establish an LPS + Lim mouse model. ${ }^{38}$ The LPS + Lim group of mice was given $50 \mathrm{mg} \mathrm{kg}{ }^{-1}$ Lim by gavage 7 days in advance. Next, we injected $0.83 \mathrm{mg} \mathrm{kg}^{-1}$ LPS into the mice by
A

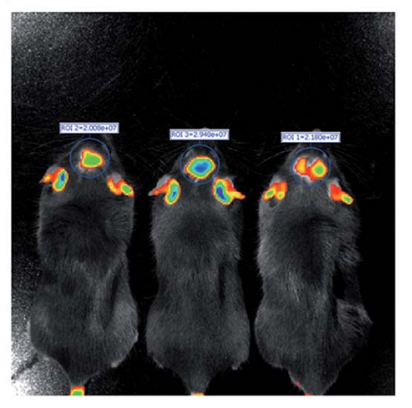

B

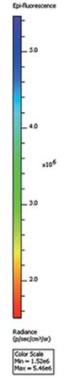

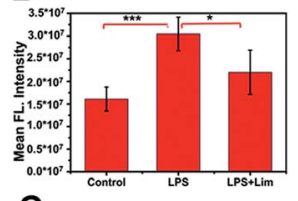

C

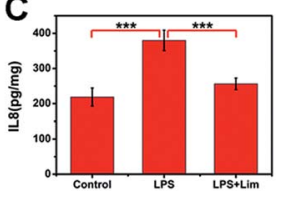

Fig. 5 Imaging of $\mathrm{O}_{3}$ and detection of IL-8 contents in the brains of mice. (A) Fluorescence imaging (pseudocolor) in the control (left), LPS (middle), and LPS + Lim (right) groups. (B) The output of fluorescence intensity in image (A). (C) Analysis of the IL- 8 content in mouse brain tissue by ELISA. The excitation wavelength filter is $570 \mathrm{~nm}$, and the emission wavelength filter is $690 \mathrm{~nm}$. The values are the mean \pm s.d. for $n=5, * p<0.05$ and $* * * p<0.001$. 
intraperitoneal injection to induce depression-like behaviors. The images showed that the fluorescence in the brain of each mouse in the LPS + Lim group was significantly lower than those of the mice in the LPS group. These results indicated that the $\mathrm{O}_{3}$ in the brains of the LPS + Lim mice was decreased. At the same time, by using DepressionScan (Clever Sys. Inc.), we found that the depression-like behaviors of mice in the LPS + Lim group was relieved. Importantly, compared with mice in the LPS group, the IL-8 level in the brains of the LPS + Lim group was also significantly decreased, which is consistent with our previous speculation. Altogether, the above results fully demonstrate that over-generated $\mathrm{O}_{3}$ in the mouse brain promotes the production of excess IL-8, which ultimately induces depression.

\section{Conclusions}

In summary, we developed a new NIR fluorescent probe (ACy7) to trace $\mathrm{O}_{3}$ in the brain tissue of small animals. ACy7 was proved to be extremely sensitive and selective to $\mathrm{O}_{3}$, as well as having good biocompatibility. Relying on these merits, we successfully applied this probe in the visualization of over produced $\mathrm{O}_{3}$ in PC12 cells under oxidative stress induced by glutamate. Importantly, we realized the in situ imaging observation of $\mathrm{O}_{3}$ in the brain tissue of mice with depression phenotypes for the first time, revealing the elevated $\mathrm{O}_{3}$ levels in mice with depression phenotypes. Furthermore, we uncovered that $\mathrm{O}_{3}$ in the brain induces mouse depression by producing excessive IL-8. This work provides strong direct evidence of a positive correlation between $\mathrm{O}_{3}$ and depression and will help to more fully elucidate the pathogenesis of depression associated with oxidative stress.

\section{Live subject statement}

All the animal experiments were carried out in accordance with the relevant laws and guidelines issued by the Ethical Committee of Shandong University and were in agreement with the guidelines of the Institutional Animal Care and Use Committee.

\section{Conflicts of interest}

There are no conflicts to declare.

\section{Acknowledgements}

This work was supported by the National Natural Science Foundation of China (21535004, 91753111, 21675105, 21475079, and 21390411) and the Key Research and Development Program of Shandong Province (2018YFJH0502), the National Major Scientific and Technological Special Project for "Significant New Drugs Development" (2017ZX09301030004) and the Natural Science Foundation of Shandong Province of China (ZR2017ZC0225).

\section{Notes and references}

1 E. J. Nestler, M. Barrot, R. J. DiLeone, A. J. Eisch, S. J. Gold and L. M. Monteggia, Neuron, 2002, 34, 13-25.
2 Y. Dowlati, N. Herrmann, W. Swardfager, H. Liu, L. Sham, E. K. Reim and K. L. Lanctôt, Biol. Psychiatry, 2010, 67, 446-457.

3 G. I. Papakostas, R. C. Shelton, G. Kinrys, M. E. Henry, B. R. Bakow, S. H. Lipkin, B. Pi, L. Thurmond and J. A. Bilello, Mol. Psychiatry, 2011, 18, 332.

4 B. C. Dickinson and C. J. Chang, Nat. Chem. Biol., 2011, 7, 504.

5 A. Oudin, D. O. Åström, P. Asplund, S. Steingrimsson, Z. Szabo and H. K. Carlsen, Environ. Health, 2018, 17, 4.

6 J. C. Chen and J. M. Samet, Eur. J. Epidemiol., 2017, 32, 943946.

7 T. Biermann, N. Stilianakis, S. Bleich, N. Thurauf, J. Kornhuber and U. Reulbach, Med. Hypotheses, 2009, 72, 338-341.

8 M. L. Mokoena, B. H. Harvey, F. Viljoen, S. M. Ellis and C. B. Brink, Psychopharmacology, 2015, 232, 2921-2938.

9 Y. H. Lim, H. Kim, J. H. Kim, S. Bae, H. Y. Park and Y. C. Hong, Environ. Health Perspect., 2012, 120, 1023-1028.

10 M. L. Mokoena, B. H. Harvey, D. W. Oliver and C. B. Brink, Metab. Brain Dis., 2010, 25, 125-133.

11 M. Szyszkowicz, International Journal of Occupational Medicine and Environmental Health, 2007, 20, 241-245.

12 L. Coppola, C. Luongo, A. Pastore, C. Masciello, R. R. Parascandola, L. Mastrolorenzo, A. Grassia, A. Coppola, M. De Biase, B. Lettieri and G. Gombos, Int. J. Geriatr. Psychopharmacol., 2010, 25, 208-213.

13 P. Wentworth Jr, J. Nieva, C. Takeuchi, R. Galve, A. D. Wentworth, R. B. Dilley, G. A. DeLaria, A. Saven, B. M. Babior, K. D. Janda, A. Eschenmoser and R. A. Lerner, Science, 2003, 302, 1053-1056.

14 P. Wentworth Jr, J. E. McDunn, A. D. Wentworth, C. Takeuchi, J. Nieva, T. Jones, C. Bautista, J. M. Ruedi, A. Gutierrez, K. D. Janda, B. M. Babior, A. Eschenmoser and R. A. Lerner, Science, 2002, 298, 2195-2199.

15 B. M. Babior, C. Takeuchi, J. Ruedi, A. Gutierrez and P. Wentworth Jr, Proc. Natl. Acad. Sci. U. S. A., 2003, 100, 3031-3034.

16 Z. Hu, G. Yang, J. Hu, H. Wang, P. Eriksson, R. Zhang, Z. Zhang and K. Uvdal, Sens. Actuators, B, 2018, 264, 419-425.

17 C. Yuan, B. Liu, F. Liu, M.-Y. Han and Z. Zhang, Anal. Chem., 2014, 86, 1123-1130.

18 X. Sun and T. D. James, J. Am. Chem. Soc., 2018, 140, 23482354.

19 X. Chen, X. Tian, I. Shin and J. Yoon, Chem. Soc. Rev., 2011, 40, 4783-4804.

20 J. Li and Y. Lu, J. Am. Chem. Soc., 2000, 122, 10466-10467.

21 N. Karton-Lifshin, L. Albertazzi, M. Bendikov, P. S. Baran and D. Shabat, J. Am. Chem. Soc., 2012, 134, 20412-20420.

22 H. Nie, W. Yang, M. Yang, J. Jing and X. Zhang, Dyes Pigm., 2016, 127, 67-72.

23 Y. Nam, B. S. Kim and I. Shin, Chem. Commun., 2016, 52, 1128-1130.

24 Y. Zhang, W. Shi, X. Li and H. Ma, Sci. Rep., 2013, 3, 2830. 25 K. Xu, S. Sun, J. Li, L. Li, M. Qiang and B. Tang, Chem. Commun., 2012, 48, 684-686.

26 A. L. Garner, C. M. St Croix, B. R. Pitt, G. D. Leikauf, S. Ando and K. Koide, Nat. Chem., 2010, 2, 422. 
27 N. Kartson-Lifshin, E. Segal, L. Omer, M. Portnoy, R. SatchiFainaro and D. Shabat, J. Am. Chem. Soc., 2011, 133, 1096010965.

28 H. Xiao, P. Li, W. Zhang and B. Tang, Chem. Sci., 2016, 7, 1588-1593.

29 A. J. Kettle, B. M. Clark and C. C. Winterbourn, J. Biol. Chem., 2004, 279, 18521-18525.

30 M. Stanciu, Y. Wang, R. Kentor, N. Burke, S. Watkins, G. Kress, I. Reynolds, E. Klann, M. R. Angiolieri, J. W. Johnson and D. B. DeFranco, J. Biol. Chem., 2000, 275, 12200-12206.

31 W. Su, Y. Zhang, Y. Chen, H. Gong, Y. Lian, W. Peng, Y. Liu, Y. Wang, Z. You, S. Feng, Y. Zong, G. Lu and C. Jiang, Behav. Brain Res., 2017, 322, 1-8.

32 J. Bosson, S. Barath, J. Pourazar, A. F. Behndig, T. Sandstrom, A. Blomberg and E. Adelroth, Eur. Respir. J., 2008, 31, 1234-1240.
33 A. Torossian, S. Ruehlmann, L. Eberhart, M. Middeke, H. Wulf and A. Bauhofer, Inflammation Res., 2004, 53(suppl. 2), S122-S125.

34 B. Kilburg-Basnyat, S. W. Reece, M. J. Crouch, B. Luo, A. D. Boone, M. Yaeger, M. Hodge, C. Psaltis, J. L. Hannan, J. Manke, M. L. Armstrong, N. Reisdorph, R. M. Tighe, S. R. Shaikh and K. M. Gowdy, Toxicol. Sci., 2018, 163, 466477.

35 R. Krishnadas and J. Cavanagh, J. Neurol., Neurosurg. Psychiatry, 2012, 83, 495-502.

36 A. H. Miller and C. L. Raison, Nat. Rev. Immunol., 2016, 16, 22-34.

37 Z. Wang, Q. Zhang, L. Yuan, S. Wang, L. Liu, X. Yang, G. Li and D. Liu, Behav. Brain Res., 2014, 274, 282-290.

38 E. Keinan, A. Alt, G. Amir, L. Bentur, H. Bibi and D. Shoseyov, Bioorg. Med. Chem., 2005, 13, 557-562. 